\title{
Coeliac disease, adenocarcinoma of jejunum and in situ squamous carcinoma of oesophagus
}

\author{
CJ O'BRIEN, S SAVERYMUTTU, HJF HODGSON, DJ EVANS \\ From the Departments of Histopathology and Gastroenterology, Royal Postgraduate Medical School, \\ Hammersmith Hospital, Du Cane Road, London W12 OHS
}

SUMMARY The development of both adenocarcinoma of the jejunum and in situ squamous carcinoma of the oesophagus in an adult coeliac patient is described. Good evidence that adenocarcinoma of jejunum occurs more frequently in patients with coeliac disease has recently become available though this association has been suggested for some time. While oesophageal carcinoma has long been associated with coeliac disease, in situ carcinoma of oesophagus has not been previously described in these circumstances. We feel that the risk of this complication, as calculated from published series, warrants a screening programme for oesophageal malignancy in adult coeliacs.

The association of coeliac disease with an increased incidence of gastrointestinal neoplasia has been confirmed by series from both Britain and Australia. ${ }^{1-4}$ There have been many reports of small intestinal adenocarcinoma in association with villous atrophy, ${ }^{5-18}$ however in very few has a definite diagnosis of coeliac disease been established. ${ }^{1617}$ The statistical association of coeliac disease with oesophageal carcinoma is strong. ${ }^{1-3}$ However, the in situ stage of this lesion has not been previously recorded in a coeliac patient.

The purpose of this report is to record the occurrence of both these neoplasms in a patient with clearly established coeliac disease and to discuss some practical and theoretical points that arise therefrom.

\section{Case report}

A 42-year-old Greek Cypriot presented in 1977 with an 18-month history of steatorrhoea and abdominal pain. In infancy he had failed to thrive and was the smallest of his family. He had been treated for psoriasis for the preceding six years. On examination, he was of short stature and showed marked finger clubbing.

The initial evaluation of his abdominal pain included barium meal, upper gastrointestinal endoscopy and lymphangiogram which were all normal. Serum amylase activity was intermittently raised, however, and an endoscopic retrograde pancreatogram showed irregularity of the main pancreatic duct. A small bowel enema was suggestive of malabsorption and a peroral jejunal biopsy was performed. This showed sub-total villous atrophy with crypt hyperplasia and a heavy lymphoplasmacytic infiltrate of the lamina propria. Numerous interepithelial lymphocytes and focal flattening of the surface enterocytes were present (Fig. 1).

Diagnoses of probable coeliac disease and chronic pancreatitis were made and a gluten-free diet and pancreatic enzyme supplements were commenced. The moderate clinical improvement which followed was not mirrored histologically on repeat jejunal biopsy. Strict supervision gluten withdrawal was therefore instituted in hospital in January 1980, and this was followed by a striking improvement in jejunal histology (Fig. 2).

During a routine follow-up examination in June 1980 he was found to have abdominal and pelvic masses. A Trucut biopsy of the latter showed a moderately well differentiated adenocarcinoma. While awaiting further investigation, signs of peritonitis developed necessitating laparotomy at which a perforated jejunal tumour, situated $15 \mathrm{~cm}$ distal to the duodenojejunal flexure, was found. The presence of a large pelvic metastasis was confirmed. Twenty centimetres of bowel were resected, in the centre of which lay a large tumour which measured $8 \times 4 \times 2 \mathrm{~cm}$ and which had ulcerated the mucosa and extended to the serosa. Histologically this tumour was a moderately well differentiated adenocarcinoma (Fig. 3). Of the eight lymph nodes present, two showed metastatic tumour. Although the adjacent 


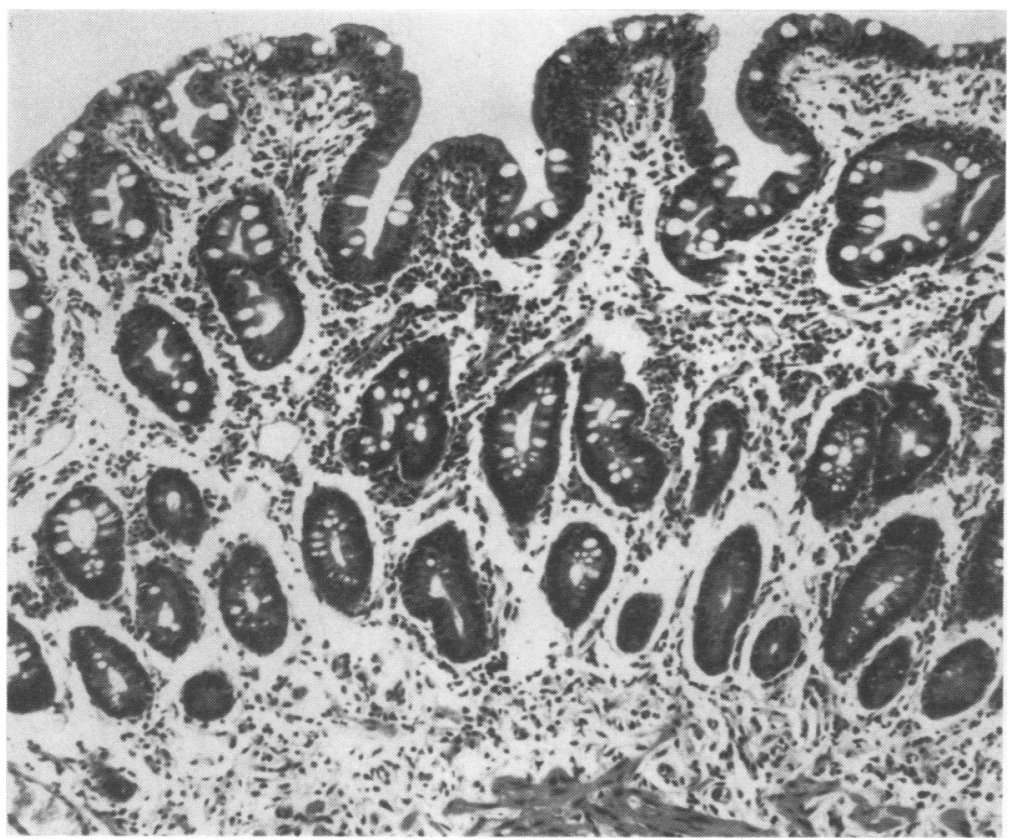

Fig. 1 Subtotal villous atrophy of jejunal mucosa with crypt hyperplasia, focal flattening and crowding of surface enterocytes and a marked interepithelial lymphocytic infiltrate. Haematoxylin and eosin $\times 150$

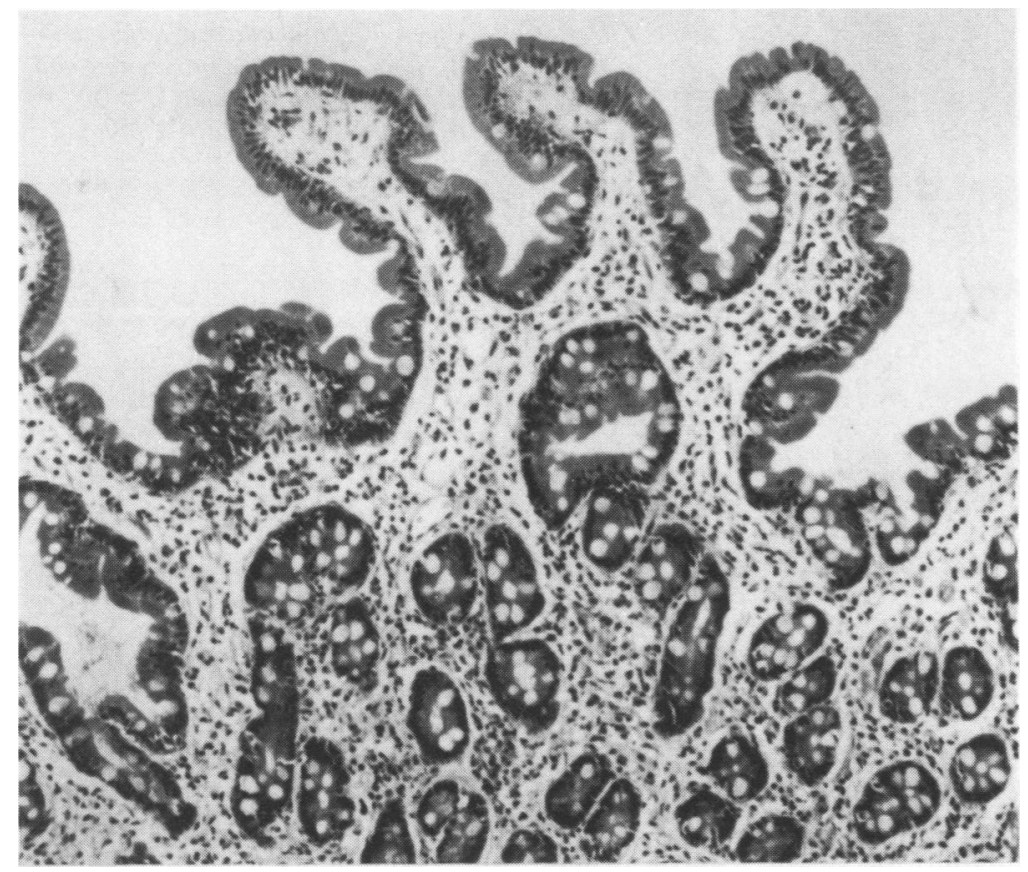

Fig. 2 Partial villous atrophy of jejunum with a lighter inflammatory infiltrate and a notable improvement in surface enterocyte morphology compared with Fig. 1. Haematoxylin and eosin $\times 150$ 


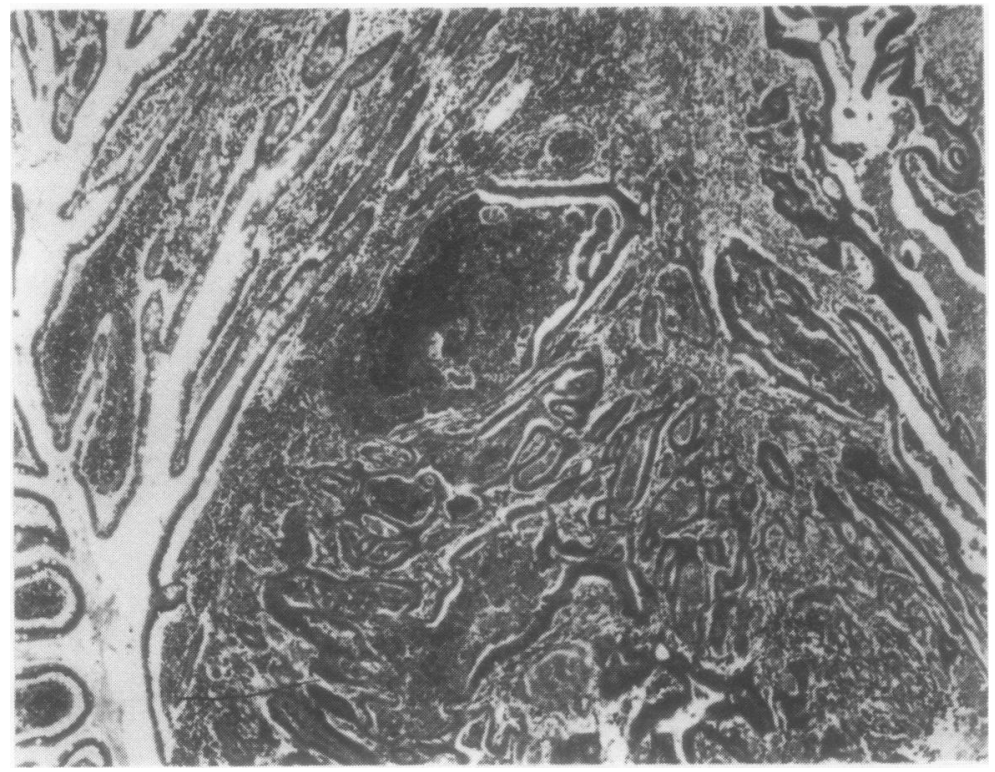

Fig. 3 Infiltrating jejunal adenocarcinoma. Haematoxylin and eosin $\times 60$

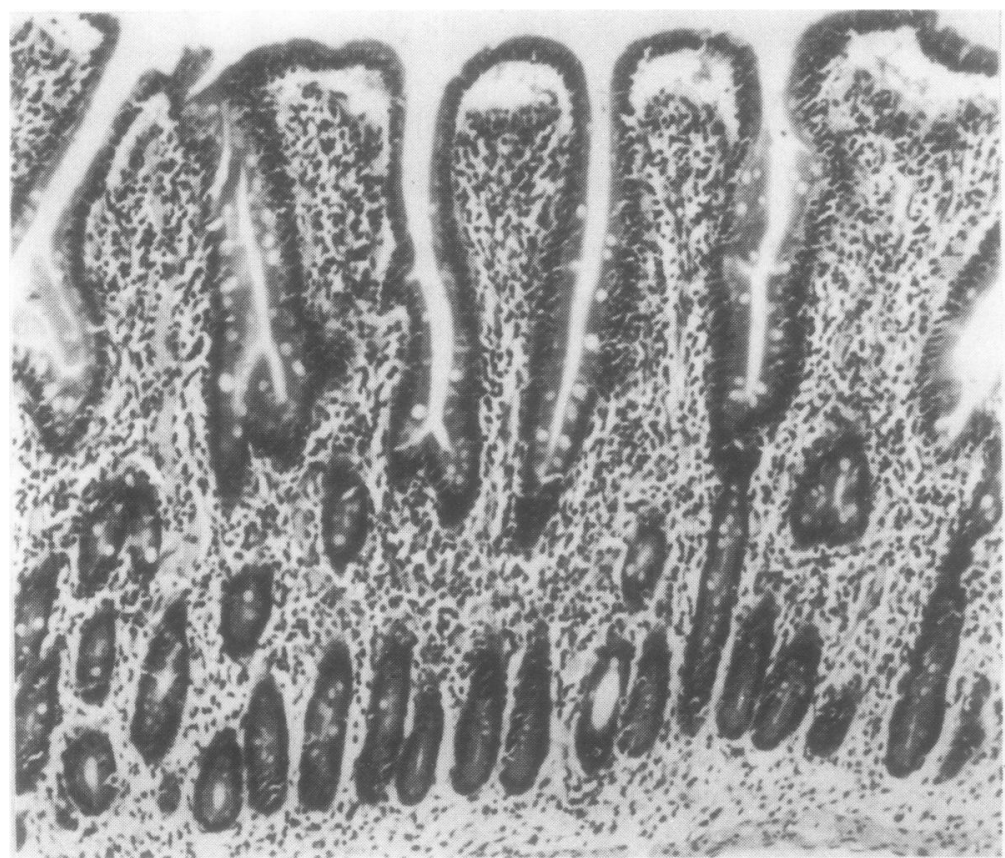

Fig. 4 Jejunal mucosa, adjacent to the tumour, showing broadening and slight shortening of villi. Haematoxylin and eosin $\times 150$

mucosa still showed partial villous atrophy there had been a considerable improvement compared with the previous biopsy (Fig. 4).

A course of fast neutron radiotherapy was given to the pelvic mass. This treatment was complicated by radiation enteritis and cystitis. A defunctioning colostomy fashioned prior to radiotherapy was closed in November 1980 at which time there was no evidence of intra-abdominal tumour. He remained reasonably well until March 1981 when he developed intestinal obstruction which, at laparotomy, was shown to be due to adhesions. At this time radiation changes were noted in the lower abdominal and pelvic structures, but again there was no evidence of 


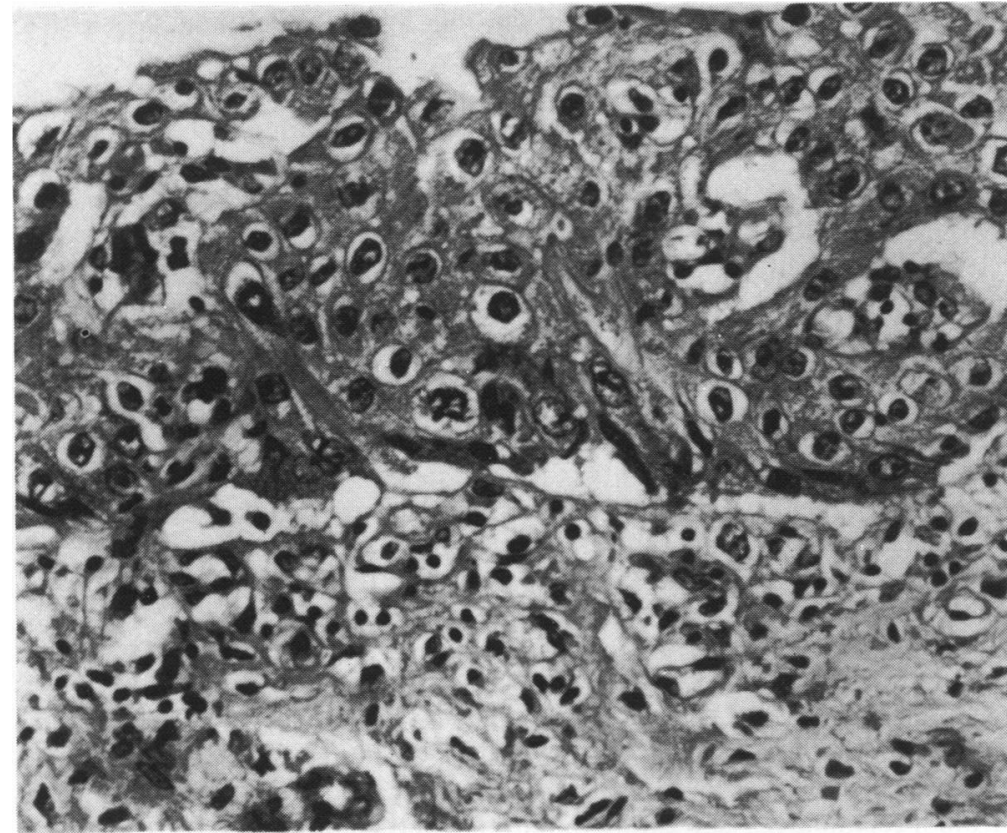

Fig. 5 Squamous carcinoma in situ of oesophagus. Markedly atypical cells occupy the full thickness of the epithelium. Haematoxylin and eosin $\times$ 400

tumour. A small bowel fistula developed postoperatively and this led to severe electrolyte problems. It became impossible to maintain nutrition and the patient died in May 1981.

\section{POST MORTEM FINDINGS}

The salient features at necropsy were the massive adhesions found in the lower abdomen and pelvis, especially involving the distal small bowel, sigmoid colon and rectum, together with the distal third of the ureters and the bladder. There was marked dilation of the small bowel proximal to the areas of densest adhesion with an enterocutaneous fistula at $215 \mathrm{~cm}$. There was bilateral ureteral and renal calyceal dilation. Mucosal reddening of the distal four $\mathrm{cm}$ of oesophagus was noted.

Sections of large intestine, bladder and lateral pelvic wall showed marked radiation changes, but no residual tumour. A left sided pyelonephritis was noted. Multiple sections of the lower oesophagus showed squamous carcinoma in situ (Fig. 5). Some downward extension of rete ridge-like structures was seen but no invasion was present. Autolysis precluded an accurate assessment of the state of the small intestinal villous architecture.

\section{Discussion}

Coeliac disease is recognised, firstly, by a lesion of the small intestinal mucosa characterised by subtotal or total loss of villi associated with crypt hyperplasia, a predominantly plasmacytic infiltrate in the lamina propria and the presence of increased numbers of lymphocytes between the surface enterocytes, which themselves are frequently abnormal. The architectural abnormality reflects a hyperproliferative mucosa ${ }^{1920}$ responding, it is thought, to a pathologically rapid loss of cells from the mucosal surface. The second pillar on which the diagnosis rests is the clinical and histological improvement which occurs on withdrawal of gluten from the diet.

The diagnosis of coeliac disease in our patient is not in doubt-a long history suggestive of malabsorption preceded his first jejunal biopsy which showed subtotal villous atrophy and both a clinical and histological improvement occurred once strict gluten withdrawal was instituted.

The psoriatic rash of this patient was troublesome and resistant to therapy for many years. It eventually remitted and remained thus despite the severity of the patient's subsequent systemic illness. It is said that ${ }^{21}$ psoriasiform and exzematous rashes may complicate coeliac disease and if so, then perhaps this is an example. On the other hand, it seems unlikely that dermatoses themselves cause malabsorption and is now recognised that psoriasis, per se, does not cause a morphological mucosal lesion of the small intestine. ${ }^{22}$

Chronic pancreatitis was diagnosed on the basis of 
abdominal pain and suggestive ERCP appearances. However, little improvement in symptoms was noted on addition of pancreatic supplements and at necropsy the pancreas appeared normal. We feel, therefore, that pancreatic disease played little part in the patient's illness.

Neoplasms of the small intestine are uncommon accounting for approximately $1 \%^{2324}$ of all gastrointestinal tumours. Carcinomas, which account for somewhat less than a third of the total, generally grow in a "napkin-ring" stenosing fashion but, due to the fluid nature of the intestinal contents, tend to present late in their course. There have been numerous reports of patients with malabsorption complicated by this tumour, ${ }^{5-18}$ but very few of these cases fulfilled the criteria for a diagnosis of coeliac disease,,$^{1617}$ though in many the syndrome described was highly suggestive..$^{131418}$ In the large series, already quoted, examining the incidence of malignancy in coeliac disease only one case of small intestinal adenocarcinoma was described. ${ }^{3}$ Recently however, evidence that adenocarcinoma of the jejunum occurs more frequently in coeliac patients than expected in the general population has come from preliminary results of the MRC trial of coeliac disease and malignancy. ${ }^{25}$

Cancers of the oesophagus usually show extensive local infiltration at diagnosis, thus accounting for the poor prognosis of this neoplasm. In situ lesions are relatively rarely reported in areas of low incidence such as the UK and USA. ${ }^{26}{ }^{27}$ However, in areas of higher incidence, such as Japan, CIS and epithelial dysplasia have been found, both in random necropsy series and, more markedly, in association with invasive carcinoma in surgical specimens. ${ }^{28}$ It has been suggested that epithelial dysplasia may progress, in a proportion of cases, to CIS and eventually to invasive carcinoma in a process analogous to that known to occur in the uterine cervix. Japanese authors caution that the possible role of irradiation should be carefully evaluated in cases of dysplasia. However, in a review of radiation injury to the alimentary tract, Berthrong et $a^{29}$ noted the following features in irradiated oesophagi-ulceration and oedema in the early stages followed later by submucosal, and sometimes serosal fibrosis with atypical fibroblasts, telangiectatic vessels and homogenisation of collagen. The epithelium quickly regenerates after ulceration and remains either rather atrophic or, more commonly, thicker than normal with parakeratosis. Apart from occasional atypical basal cells they did not note any epithelial dysplasia. The thoracic region was well outside the irradiation field in our patient and this is confirmed by the total absence of irradiation changes in the oesophagus when compared with the extensive changes seen in the lower abdominal and pelvic regions.

In the large series already quoted, oesophageal carcinoma, along with small intestinal lymphoma, were the malignancies most frequently associated with coeliac disease. Both neoplasms occurred significantly more frequently than expected in control populations and largely accounted for the significantly greater number of all malignancies that also occurred in the coeliac groups. The UK is an area of low incidence for oesophageal carcinoma as indicated by the 1973 Cancer Registration figures for England and Wales (7.3 per 100000 for men and $5 \cdot 2$ per 100000 for women). A relative risk of 20 for oesophageal tumours in coeliacs can be calculated from the Birmingham series, ' indicating an incidence of approximately 120 per 100000 . In view of this risk and the generally very poor prognosis of invasive oesophageal carcinoma, a programme of active screening of adult coeliac patients may be indicated. According to the above figures, one new case should be detected per 1000 patients screened. This yield could be considerably increased by confining screening to patients in the "at risk" age group which according to the published series is the fifth decade and onwards. Such screening might identify carcinomas at an in situ and therefore curable stage. It would also, perhaps, throw more light on the incidence of oesophageal epithelial dysplasia in coeliac disease and on the rate and frequency of its progression to carcinoma.

The important features of this case are, firstly, that it records the hitherto unreported concurrence of in situ squamous carcinoma of the oesophagus and coeliac disease; secondly, that this finding suggests a possible role for cytological screening of these patients for oesophageal malignancy; and thirdly, that the case supports the suspected association of coeliac disease and small intestinal carcinoma.

\section{References}

' Harris OD, Cooke WT, Thompson H, Waterhouse JAH. Malignancy in adult coeliac disease and idiopathic steatorrhoea. Am J Med 1967;42:899-911.

2 Holmes GKT, Stokes PL, Sarahan TM, Prior P, Waterhouse JAH, Cooke WT. Coeliac disease, gluten-free diet, and malignancy. Gut 1976;17:612-9.

${ }^{3}$ Selby WS, Gallagher ND. Malignancy in a 19-year experience of adult coeliac disease. Digest Dis Sci 1979;24:684-8.

${ }^{4}$ Cooper BT, Holmes GKT, Ferguson R, Cooke WT. Coeliac disease and malignancy. Medicine 1980;59:249-61.

${ }^{5}$ Case records of the Massachusetts General Hospital. N Engl J Med 1958;259:491-5.

- Joske RA. Primary carcinoma of the jejunum with atrophic jejunitis and intestinal malabsorption. Gastroenterology 1960;38:810-6.

' Girdwood RH, Delamore IW, Wynn Williams A. Jejunal biopsy in malabsorptive disorders of the adult. Br Med J 1961;1:319-23. 
${ }^{8}$ Moertel EG, Hargraves MM. Coexistence of adenocarcinoma of the jejunum and non-tropical sprue. JAMA 1961;176:612-4.

9 Blackwell JB. Malabsorption in the presence of primary carcinoma of the small bowel. Gut 1961;2:377.

${ }^{10}$ Fric P, Bednar B, Niederle B, Lepsik J. Jejunal adenocarcinoma in a woman with non-tropical sprue. Gastroenterology $1963 ; 44: 330-4$.

"Brzechwa-Ajdukiewicz A, McCarthy CF, Austad W, Cornes J, Harrison WJ, Read AEA. Carcinoma, villous atrophy and steatorrhoea. Gut 1966;7:572-7.

${ }^{12}$ Lee FD. Nature of the mucosal changes associated with malignant neoplasms in the small intestine. Gut 1966;7:361-7.

${ }^{13}$ Asch T, Seaman WB. Ideopathic steatorrhoea and small bowel cancer. Radiology 1971;100:271-5.

${ }^{14}$ Kenwright S. Coeliac disease and small bowel carcinoma. Postgrad Med J 1972;48:673-7.

is Petreshock EP, Pessah M, Menachemi E. Adenocarcinoma of the jejunum associated with non-tropical spure. Dig Dis 1975;20:796-802.

${ }^{16}$ Collins SM, Hamilton JD, Lewis TD, Laufer I. Small bowel malabsorption and gastro-intestinal malignancy. Radiology 1978;126:603-9.

17 Javier J, Lukie B. Duodenal adenocarcinoma complicating coeliac sprue. Dig Dis Sci 1980;25:150-3.

${ }^{18}$ Holmes GKT, Dunn GI, Cochel R, Brookes VS. Adenocarcinoma of the upper small bowel complicating coeliac disease. Gut 1980;21:1010-6.

${ }^{19}$ Wright N, Watson A, Morely A, Appleton D, Marks J, Douglas A. The cell cycle time in the flat (avillous) mucosa of the human small intestine. Gut 1973;14:603-6.
${ }^{20}$ Wright N, Watson A, Morley A, Appleton D, Marks J. Cell kinetics in flat (avillous) mucosa of the human small intestine. Gut 1973;14:701-10.

${ }^{21}$ Marks J, Shuster S. Intestinal malabsorption and the skin. Gut 1971;12:938-47.

${ }^{22}$ Marks J, Shuster S. Small intestinal mucosal abnormalities in various skin diseases-fact or fancy? Gut 1970;11:281-91.

${ }^{23}$ Darling RC, Welsh CE. Tumours of the small intestine. $N$ Engl $J$ Med 1959;260:397.

${ }^{24}$ Brookes VS, Waterhouse JAH, Powell DJ. Malignant lesions of the small intestine. BrJ Surg 1968;55:405-10.

${ }^{25}$ Swinson CM, Slavin G, Coles EC, Booth CC. Coeliac disease and malignancy. Gut 1981;22:A872.

${ }^{26}$ Sotus PC, Majmuder B, Symbas PN. Carcinoma in situ of the oesophagus. JAMA 1978;239:335-6.

${ }^{27}$ Ushigome S, Spjut HJ, Noon GP. Extensive dysplasia and carcinoma in situ of oesophageal epithelium. Cancer 1967;20:1023-9.

${ }^{28}$ Sato E, Tokunaga M, Sakae K, Mukada T, Sasano N. Epithelial dysplasia in cancerous and non-cancerous oesophagi. Tohoku J Exp Med 1978;124:117-28.

${ }^{29}$ Berthrong M, Fajardo LF. Radiation injury in surgical pathology, Part II, Alimentary tract. Am J Surg Pathol 1981;5:153-78.

Requests for reprints to: $\mathrm{Dr}$ CJ O'Brien, Royal Postgraduate Medical School, Hammersmith Hospital, Du Cane Road, London W12 0HS, England. 